\title{
Monitoring guanine photo-oxidation by enantiomerically resolved $R u(I I)$ dipyridophenazine complexes using inosine-substituted oligonucleotides
}

Article

Accepted Version

Keane, P. M., Poynton, F. E., Hall, J. P., Clark, I. P., Sazanovich, I. V., Towrie, M., Gunnlaugsson, T., Quinn, S. J., Cardin, C. J. and Kelly, J. M. (2015) Monitoring guanine photooxidation by enantiomerically resolved $\mathrm{Ru}(\mathrm{II})$ dipyridophenazine complexes using inosine-substituted oligonucleotides. Faraday Discussions, 185. pp. 455-469. ISSN 1364-5498 doi: https://doi.org/10.1039/c5fd00085h Available at https://centaur.reading.ac.uk/40947/

It is advisable to refer to the publisher's version if you intend to cite from the work. See Guidance on citing.

To link to this article DOI: http://dx.doi.org/10.1039/c5fd00085h

Publisher: The Royal Society of Chemistry

All outputs in CentAUR are protected by Intellectual Property Rights law, including copyright law. Copyright and IPR is retained by the creators or other copyright holders. Terms and conditions for use of this material are defined in the End User Agreement. 


\section{www.reading.ac.uk/centaur}

\section{CentAUR}

Central Archive at the University of Reading

Reading's research outputs online 


\title{
Monitoring guanine photo-oxidation by enantiomerically resolved $\mathrm{Ru}(\mathrm{II})$ dipyridophenazine complexes using inosine- substituted oligonucleotides
}

\author{
${ }_{5}$ Páraic M. Keane, ${ }^{\text {a,b* }}$ Fergus E. Poynton, ${ }^{\text {b,c }}$ James P. Hall, ${ }^{\text {b,d }}$ Ian P. Clark, ${ }^{\text {c }}$ Igor V. \\ Sazanovich, ${ }^{\mathrm{c}}$ Michael Towrie, ${ }^{\mathrm{c}}$ Thorfinnur Gunnlaugsson, ${ }^{\mathrm{b}, \mathrm{c}}$ Susan J. Quinn, ${ }^{\mathrm{e}}$ \\ Christine J. Cardin ${ }^{\mathrm{b}} *$ and John M. Kelly ${ }^{\mathrm{a} *}$ DOI: 10.1039/b000000x [DO NOT \\ ALTER/DELETE THIS TEXT]
}

The intercalating $\left[\mathrm{Ru}(\mathrm{TAP})_{2}(\mathrm{dppz})\right]^{2+}$ complex can photo-oxidise guanine in DNA, 10 although in mixed-sequence DNA it can be difficult to understand the precise mechanism due to uncertainties in where and how the complex is bound. Replacement of guanine with the less oxidisable inosine (I) base can be used to understand the mechanism of electron transfer (ET). Here the ET has been compared for both $\Lambda$ - and $\Delta$ - enantiomers of $\left[\mathrm{Ru}(\mathrm{TAP})_{2}(\mathrm{dppz})\right]^{2+}$ in a set of 15 sequences where guanines in the the readily oxidisable GG step in $\{\text { TCGGCGCCGA }\}_{2}$ have been replaced with I. The ET has been monitored using picosecond and nanosecond transient absorption and ps-time-resolved IR spectroscopy. In both cases inosine replacement leads to a diminished yield, but the trends are strikingly different for $\Lambda$ - and $\Delta$ - complexes.

\section{${ }_{20} 1$ Introduction}

The non-covalent binding of metal complexes to double-stranded DNA is a challenging example of supramolecular chemistry. As has been amply shown over the years it is not always straightforward to determine precisely how the molecule 25 binds to the duplex (intercalation, semi-intercalation, binding in the minor- or majorgrooves, simple external binding). ${ }^{1}$ A further interesting aspect for octahedral complexes with bidentate ligands is the fact that two enantiomers exist, opening up the possibility of stereo-specific binding. ${ }^{2}$ As many of these complexes can act as photosensitisers of DNA damage, it is vital that one knows as much as possible 30 about the location, mode of binding and precise orientation of the molecule relative to the target part of the nucleic acid. In this connection crystallography studies can be of great use. ${ }^{3}$ However, given the sensitivity of binding to the surrounding medium and to concentrations of the constituents, it is possible that the precise noncovalent interaction of the metal complex with the polynucleotide in solution may be

35 different. (For example semi-intercalation may be favoured in the crystal). In this paper we extend our studies of factors determining photo-induced one-electron oxidation of DNA by $\left[\mathrm{Ru}(\mathrm{TAP})_{2}(\mathrm{dppz})\right]^{2+}$ (1. Fig. 1; TAP $=1,4,5,8$-tetraazaphenanthrene; $\mathrm{dppz}=(\mathrm{dppz}=$ dipyrido[3,2-a:2',3'-c]phenazine $)$ using ultrafast transient spectroscopy, by examining the effect of replacing the readily oxidisable

40 guanine by inosine. As we will show, this substitution can have surprising effects which are due to the supramolecular association of the metal complex enantiomer with the duplex DNA. Developing our understanding of the mechanism for such photo-sensitised DNA damage is also important for phototherapeutic applications. ${ }^{4}$ 
Dipyridophenazine complexes of ruthenium, such as $\left[\mathrm{Ru}(\mathrm{phen})_{2}(\mathrm{dppz})\right]^{2+}(\mathrm{phen}=$ 1,10 -phenanthroline) or $\left[\mathrm{Ru}(\mathrm{TAP})_{2}(\mathrm{dppz})\right]^{2+}$ bind strongly to DNA by intercalation of the dppz ligands between the DNA base-pairs. ${ }^{5}$ Although structurally similar, the phen and TAP derivatives have markedly different photophysical properties, and it 5 has been shown that racemic 1 photo-oxidises guanine in either polynucleotide DNA or in mononucleotide GMP, ${ }^{6}$ which results in luminescence quenching. The reduced metal complex and oxidised guanine species can then be observed using picosecond transient visible absorption and time-resolved IR, respectively. Other TAP complexes have been shown to form a covalent photo-adduct with guanine upon

${ }_{10}$ photolysis. $^{7}$ The proposed mechanism for ET is shown in Scheme 1, although it is not at this stage clear whether the process proceeds by direct or proton-coupled ET.

$$
\begin{aligned}
& {\left[\operatorname{Ru}^{\prime \prime}\left(\operatorname{TAP}_{2}(\mathrm{dppz})\right]^{2+} \stackrel{\text { MLCT }}{\longrightarrow}\left[\mathrm{Ru}^{\prime \prime \prime}(\mathrm{TAP})\left(\mathrm{TAP}^{*-}\right)(\mathrm{dppz})\right]^{2+*}\right.}
\end{aligned}
$$

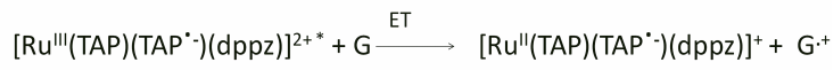

$$
\begin{aligned}
& {\left[\operatorname{Ru}^{\prime \prime}(\operatorname{TAP})\left(\operatorname{TAP}^{*}\right)(\mathrm{dppz})\right]^{+}+\mathrm{G}^{+} \stackrel{\text { bET }}{\longrightarrow}\left[\mathrm{Ru}^{\prime \prime}\left(\mathrm{TAP}_{2}(\mathrm{dppz})\right]^{2+}+\mathrm{G}\right.}
\end{aligned}
$$

Scheme 1 A mechanism for the photo-oxidation of $\mathrm{G}$ by $\left[\operatorname{Ru}(\mathrm{TAP})_{2}(\mathrm{dppz})\right]^{2+}$

We recently compared the resolved $\Lambda$ and $\Delta$ enantiomers for the first time to show that the enantiomeric conformation and DNA sequence can modulate the electron transfer considerably. ${ }^{6 e}$ We have since shown that efficient formation of the reduced 20 species requires the complex to be bound at a G-containing site while ET over a longer distance results in a significant reduction in yield and rate. ${ }^{6 f}$ Accurate understanding of the photo-oxidation requires knowledge of where and how the complex is bound. This problem has been helped greatly since the precise geometry of the binding site for such $[\mathrm{Ru}(\mathrm{II})(\mathrm{dppz})]^{2+}$ complexes has been defined recently 25 from X-Ray crystallography. ${ }^{3}$ The first such structure reported for a DNA-bound $\mathrm{Ru}(\mathrm{II}) \mathrm{dppz}$ complex was for $\Lambda-\mathbf{1}$ in the presence of the TCGGCGCCGA $_{2}$ decamer duplex. $^{3 a}$ The crystal structure of $\Lambda-\mathbf{1}$ bound to $\{\text { TCGGCGCCGA }\}_{2}$ shows intercalation at the terminal T1C2;G9A10 step, and semi-intercalation of the TAP ligand at the G3G4 step. The \{TCGGCGCCGA $\}_{2}$ duplex is also notable for 30 containing a GG step as the semi-intercalation site, a well-known damage hotspot due to the lowered oxidation potential of the $5^{\prime}-\mathrm{G} .{ }^{8}$

In our recent study on the enantiomers of $\mathbf{1}$ we suggested that binding of the $\Lambda$ complex close to GG sites may be the cause of increased yields of ET. Therefore, in this current study, we have substituted G3 and G4 in \{TCGGCGCCGA $\}_{2}$ with 35 inosine in order to observe the effect on the ET. Inosine is structurally similar to guanine, but with the $\mathrm{NH}_{2}$ at the 2 position removed, and is reported to have an oxidation potential $200 \mathrm{mV}$ higher than guanine. ${ }^{9}$ It still forms a base-pair with $\mathrm{C}$, and can be substituted into a DNA sequence. It is not expected to perturb the structure of the DNA, ${ }^{10}$ although a slight bending ${ }^{11}$ and decrease in melting 40 temperature may be found due to the removal of one Watson-Crick hydrogen bond. The strategy of inosine substitution has been used previously in order to assign sites of damage and learn information on ET mechanism. ${ }^{12}$ However, our previous crystallographic data has revealed that, in some circumstances, and in particular for 
the $\Lambda$ enantiomer, slight changes in sequence can have a large effect on the binding modes. ${ }^{3 \mathrm{~b}}$ As replacing $\mathrm{G}$ with I means the removal of one $\mathrm{NH}_{2}$ group, the CI basepair has been noted to be sterically and electronically similar to a TA base-pair when viewed from the minor groove, the site from which these complexes approach

5 (Figure 2). ${ }^{13}$ Therefore, it is intriguing to observe the effect of inosine substitution on the ET for each enantiomer.

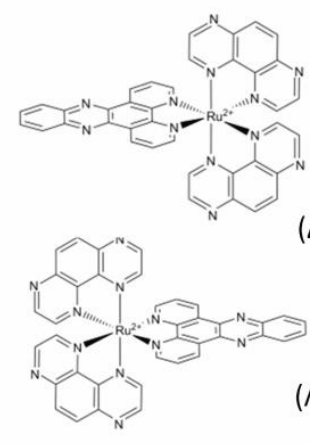

$\left\{\mathrm{T}_{1} \mathrm{C}_{2} \mathrm{G}_{3} \mathrm{G}_{4} \mathrm{C}_{5} \mathrm{G}_{6} \mathrm{C}_{7} \mathrm{C}_{8} \mathrm{G}_{9} \mathrm{~A}_{10}\right\}_{2}$ $\left\{\mathrm{T}_{1} \mathrm{C}_{2} \mathrm{I}_{3} \mathrm{G}_{4} \mathrm{C}_{5} \mathrm{G}_{6} \mathrm{C}_{7} \mathrm{C}_{8} \mathrm{G}_{9} \mathrm{~A}_{10}\right\}_{2}$ $\left\{\mathrm{T}_{1} \mathrm{C}_{2} \mathrm{G}_{3} \mathrm{I}_{4} \mathrm{C}_{5} \mathrm{G}_{6} \mathrm{C}_{7} \mathrm{C}_{8} \mathrm{G}_{9} \mathrm{~A}_{10}\right\}_{2}$ $\left\{\mathrm{T}_{1} \mathrm{C}_{2} \mathrm{I}_{3} \mathrm{I}_{4} \mathrm{C}_{5} \mathrm{G}_{6} \mathrm{C}_{7} \mathrm{C}_{8} \mathrm{G}_{9} \mathrm{~A}_{10}\right\}_{2}$

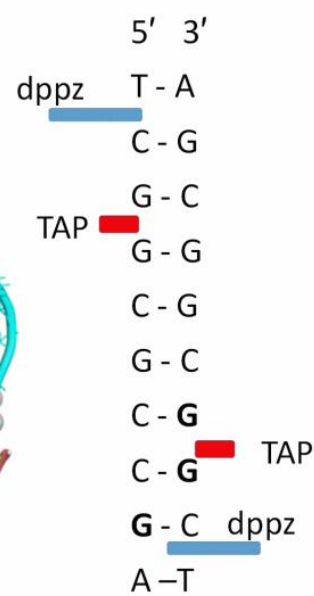

$A-T$

Fig. 1 Structures of $\Lambda$ - and $\Delta$-[Ru(TAP $\left.)_{2}(\mathrm{dppz})\right]^{2+}$; ODNs A, I3, I4 and I34; crystal structure of $\Lambda$ $\left[\operatorname{Ru}(\mathrm{TAP})_{2}(\mathrm{dppz})\right]^{2+}$ in ODN $\mathbf{A}$; intercalation and semi-intercalations sites in crystal structure.

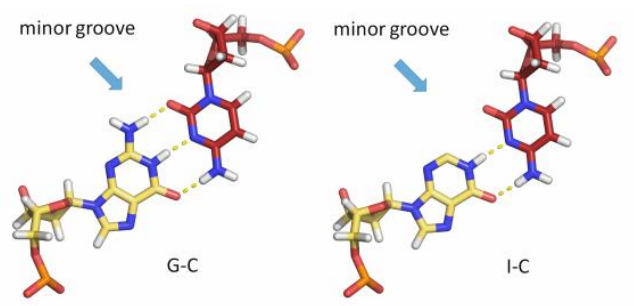

Fig. 2 comparison of the G-C and I-C base pairs with respect to the minor groove

To study the photo-sensitised oxidation process we have used ultrafast time15 resolved spectroscopy. Transient absorption (TrA) is used to monitor the visible region spectroscopic changes at the polypyridyl complex, while time-resolved infrared (TRIR) is especially useful for following chemical changes in the nucleobases. ${ }^{14} \mathrm{D}_{2} \mathrm{O}$ is used as solvent due to strong absorptions by $\mathrm{H}_{2} \mathrm{O}$ in the 1650 $\mathrm{cm}^{-1}$ region. Typical concentrations of $400 \mu \mathrm{M}\left[\mathrm{Ru}(\mathrm{II})(\mathrm{TAP})_{2}(\mathrm{dppz})\right]^{2+}, 500 \mu \mathrm{M}$ 20 DNA duplex were used to allow TrA and TRIR to be performed on comparable samples. Statistically under these conditions only one complex is bound per duplex.

\section{Experimental}


The $\Lambda / \Delta-\left[\operatorname{Ru}(\mathrm{TAP})_{2}(\mathrm{dppz})\right]^{2+}$ complex was synthesised and resolved using modified literature methods. ${ }^{6 \mathrm{e}}$ Time-resolved measurements were recorded on the ULTRA apparatus at the Central Laser Facility (Harwell, UK), described in detail elsewhere. ${ }^{15}$ Briefly, the spectrometer comprises of a $10 \mathrm{kHz}$ repetition rate titanium 5 sapphire amplifier producing $0.8 \mathrm{~mJ}$ output with $40 \mathrm{fs}$ pulse duration, at $800 \mathrm{~nm}$. Optical parametric amplifiers and second harmonic generation of the $800 \mathrm{~nm}$ created the mid-infrared radiation and $400 \mathrm{~nm}$ femtosecond pump pulses for psTRIR measurements. For the ps-TrA measurements, part of the titanium:sapphire laser output beam was used to generate a white light continuum in $\mathrm{CaF}_{2}$ crystal. The

${ }_{10}$ polarisation of the pump pulses at the sample were at the magic angle relative to the probe. For nanosecond experiments excitation was at $355 \mathrm{~nm}$ and $1 \mathrm{~ns}$ pulse length. The excitation pulse energy at the sample was ca $0.8-1 \mu \mathrm{J}$ and focused to approx. $100 \mu \mathrm{m}$ spot size. NsTrA spectra for $\Lambda / \Delta-\mathbf{1}$ bound to ODNs I3 and $\mathbf{I 4}$ were recorded using the time-resolved multiple probe spectroscopy ( $\mathrm{TR}^{\mathrm{M}} \mathrm{PS}$ ) configuration at 400

$15 \mathrm{~nm}$ excitation. ${ }^{15 \mathrm{~b}}$ The set-up for psTrA/TRIR and nsTrA is identical to those described in detail recently. ${ }^{6, f}$ Data analysis was performed using OriginPro 8.5. Single exponential growth kinetics were calculated at single wavelengths using the Marquardt-Levenburg algorithm.

\section{${ }_{20}$ Results}

The visible transient absorption (TrA) difference spectrum observed shortly after $400 \mathrm{~nm}$ laser pulse excitation of $\left[\mathrm{Ru}(\mathrm{TAP})_{2}(\mathrm{dppz})\right]^{2+}$ in aqueous buffer $(\mathrm{pH} 7)$ solution shows strong bleaching between approximately $420 \mathrm{~nm}$ and $500 \mathrm{~nm}$ and broad absorption at longer wavelengths with a maximum at ca. $600 \mathrm{~nm}$ (Fig. 3 \& $\left.{ }_{25} 4\right) .{ }^{6 e}$ Closely similar spectra are found at times shortly after the laser pulse when the complex is bound to any of the oligodeoxynucleotides (ODN) used in this study (Figure 3 shows spectra recorded 20 ps after laser excitation). This species may be assigned as the $\left[\mathrm{Ru}(\mathrm{III})(\mathrm{TAP})\left(\mathrm{TAP}^{*^{-}}\right)(\mathrm{dppz})\right]^{2+*}{ }^{3} \mathrm{MLCT}$ excited state localised on the TAP ligand. ${ }^{6}$ At later times a new feature emerges with an absorption maximum at $30515 \mathrm{~nm}$, which is assigned to [Ru(II)(TAP)(TAP $\left.\left.{ }^{-}\right)(\mathrm{dppz})\right]^{+}$, formed by reduction of the complex's excited state through electron transfer from guanine. The extent to which this feature develops (which can be monitored by measuring $\triangle \mathrm{OD}(515 \mathrm{~nm})$ : $\triangle \mathrm{OD}(600 \mathrm{~nm})$ ratio) is very sensitive to the ODN to which the complex is bound. ${ }^{6 e}$ It may also be noted that the intensity of the negative-going band in the $420-500 \mathrm{~nm}$ 35 region also diminishes strongly as the electron transfer reaction proceeds. This diminution of the bleach band is due to the reduced species absorbing more strongly than the excited state. This change (measured using the absorbance ratio at $20 \mathrm{ps}$ and at $2500 \mathrm{ps}$ ) can therefore be used as a means to measure the relative yield of electron transfer (see Figure 3 and Table 1, data for $\left\{(\mathrm{GC})_{5}\right\}_{2}$ and $\left\{\mathrm{G}_{5} \mathrm{C}_{5}\right\}_{2}$ have also been 40 included for comparative purposes). ${ }^{\dagger}$ This data shows that for $\Lambda$-1 the relative yield decreases very strongly in the order A $>$ I3 $>$ I4 $>$ I34, with the yield in the diinosine substituted compound being very small indeed. By contrast for $\Delta-\mathbf{1}$, the yields of electron transfer with I3, I4 and I34 are quite similar and approximately half that found with $\mathbf{A}$.

45 Kinetics of the rate of forward ET can be readily measured by monitoring the increase in absorption at $515 \mathrm{~nm}$. It may be observed that for $\Lambda$-1 the rate is somewhat slower for $\mathbf{I} 3$ than it is for $\mathbf{A}$ and $\mathbf{I 4}$, while for $\Delta-\mathbf{1}$ the rate for $\mathbf{I} 3$ is faster 
than for A and $\mathbf{I} 4$ (Table 2).

The transient absorption and bleaching signals decay in the nanosecond time domain, showing that the system is reversible. In all cases this decay is more than an order of magnitude faster than the excited state free in solution or when bound to a ${ }_{5}$ guanine-deficient duplex such as $\{\text { polydA-dT }\}_{2} \cdot{ }^{6 \mathrm{~b}}$ Such rapid decay is found to occur at both $515 \mathrm{~nm}$ and at $600 \mathrm{~nm}$ and first order rate constants measured at these wavelengths are the same within error. For $\Lambda \mathbf{- 1}$ the rate is twice as fast for $\mathbf{I} \mathbf{3}$ as it is for $\mathbf{A}$, while for $\mathbf{I 4}$ it is significantly smaller. For $\Delta-\mathbf{1}$ the rates are significantly faster and the differences between the ODNs are not so large. For both enantiomers 10 the $\mathbf{I 3 4}$ system has a lifetime of ca. $50 \mathrm{~ns}$.

By contrast with TrA experiments, TRIR allows the monitoring of spectroscopic changes on the ODNs as well as on the metal complex. The latter dominate the spectra below $1500 \mathrm{~cm}^{-1}$ with many sharp bleaches and transients, including a large broad absorption at $1460 \mathrm{~cm}^{-1}$ found in both the MLCT excited state and the reduced 15 complex (Figure 5). ${ }^{6 e}$ Strong bleaching is also observed between $1640 \mathrm{~cm}^{-1}$ and $1700 \mathrm{~cm}^{-1}$, where the $\mathrm{C}=\mathrm{O}$ absorptions of $\mathrm{C}$ and $\mathrm{G}$ or I occur. (Figure 2). As the DNA is not directly excited at $400 \mathrm{~nm}$, these bleaches can be attributed to changes in the structure of the G-C or I-C base pairs upon photo-excitation of the bound complex. The presence of these bands at early times ( $20 \mathrm{ps})$ before ET has occurred 20 must be due to an interaction between the photo-excited metal complex and the nucleobases in the binding site. As previously reported ${ }^{6 \mathrm{e}}$ the subsequent electron transfer process leads to characteristic increase in the bleaching of these carbonyl bands and the appearance of an absorption band at approximately $1700 \mathrm{~cm}^{-1}$, the latter being assigned to the one-electron oxidised guanine. ${ }^{16}$ Such features are found ${ }_{25}$ for $\mathbf{A}$ and for I3 ODNs with both enantiomers. The situation is less clear for the $\mathbf{I} 4$ and I34. As expected from the TrA studies, the reduced ET yield with I4 is consistent with the modest additional bleaching between 20 and 1000 ps for the $\Lambda$ enantiomer. For the $\mathbf{I 3 4}$ samples there is increased bleaching for the $\Delta$ enantiomer, although the band at $1700 \mathrm{~cm}^{-1}$ is not well developed. It may be noted that in this 30 case the bleaching pattern does differ significantly from that of the other oligonucleotides, perhaps indicative of a different binding site. 

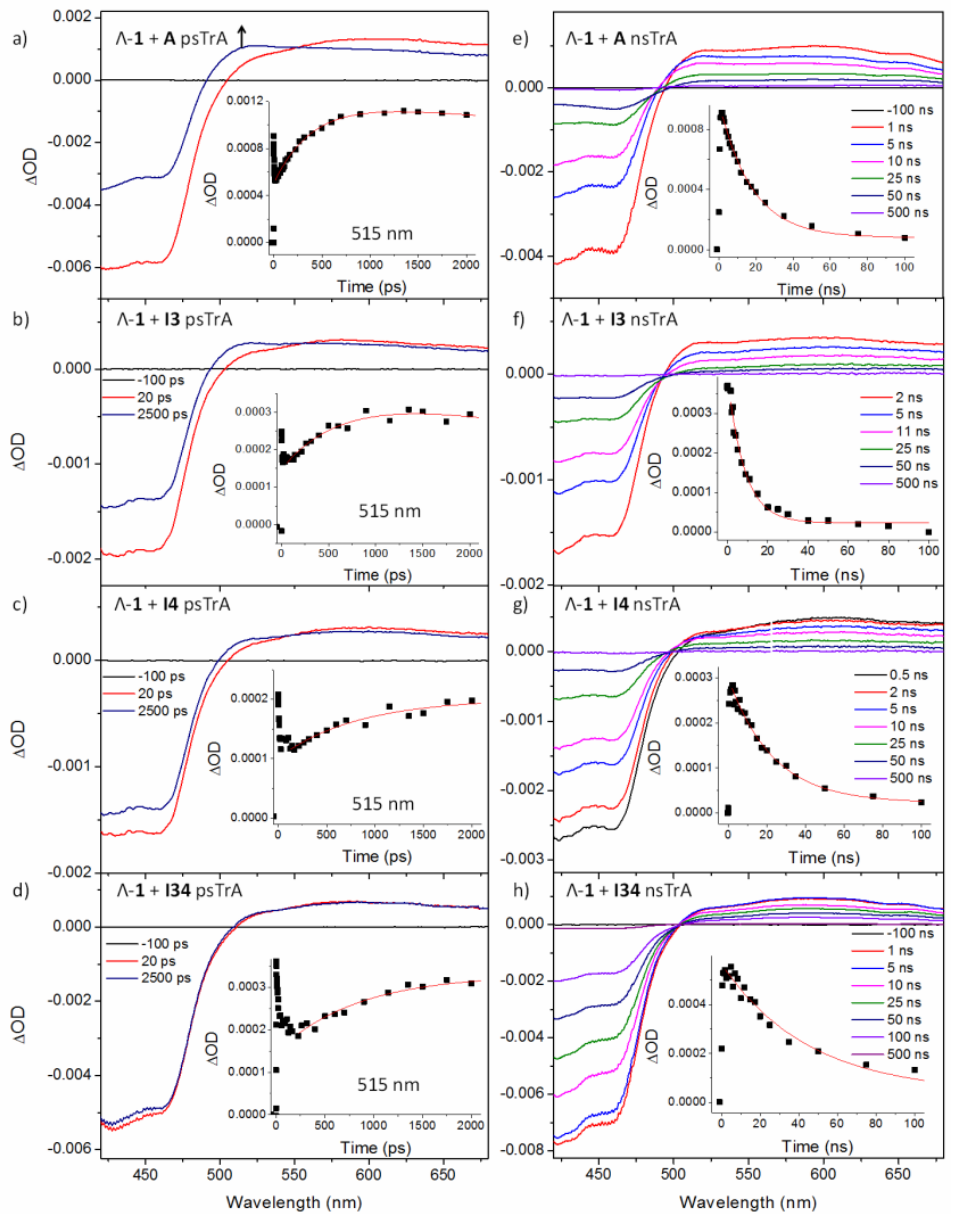

Fig. 3 Comparison of ps/ns-TrA spectra for of $\Lambda$ - $\left[\operatorname{Ru}(\mathrm{TAP})_{2}(\mathrm{dppz})\right]^{2+}$ in the presence of $\mathbf{A}, \mathbf{I 3}, \mathbf{I} \mathbf{4}$ or I34; $\lambda_{\text {exc }}=400 \mathrm{~nm}(\mathrm{a}, \mathrm{b}, \mathrm{c}, \mathrm{d}, \mathrm{f}, \mathrm{g}) ; 355 \mathrm{~nm}(\mathrm{e}, \mathrm{h})$ at $1 \mu \mathrm{J}$. Inset: kinetics at $515 \mathrm{~nm}$ (note the differences in strength of signal in ps-TrA data). Data in the presence of $\mathbf{A}^{6 \mathrm{e}}$ shown for comparative purposes.

Table 1. Relative ET yields determined from bleach intensities ${ }^{\mathrm{a}}$

\begin{tabular}{lllllll}
\hline complex & $\mathbf{A}^{\mathrm{b}}$ & $\mathbf{I 3}$ & $\mathbf{I 4}$ & $\mathbf{I 3 4}$ & $(\mathbf{G C})_{\mathbf{5}}{ }^{\mathrm{b}}$ & $\mathbf{G}_{\mathbf{5}} \mathbf{C}_{\mathbf{5}}{ }^{\mathrm{b}}$ \\
\hline $\boldsymbol{\Lambda}$ & 0.44 & 0.28 & 0.14 & 0.02 & 0.22 & 0.74 \\
$\boldsymbol{\Delta}$ & 0.57 & 0.32 & 0.35 & 0.25 & 0.62 & 0.64 \\
\hline
\end{tabular}


${ }^{\mathrm{a}}$ Calculated as $\left(\Delta \mathrm{OD}_{20 \mathrm{ps}}-\Delta \mathrm{OD}_{2500 \mathrm{ps}}\right) / \Delta \mathrm{OD}_{20 \mathrm{ps}}$ at $460 \mathrm{~nm}$. ${ }^{\mathrm{b}}$ values calculated from data in Keane et al. ${ }^{6 e}$

Table 2. Fitted lifetimes for $\operatorname{TrA}$ and TRIR spectra of $\Lambda$ - and $\Delta-\left[\operatorname{Ru}(\mathrm{TAP})_{2}(\mathrm{dppz})\right]^{2+}$ bound to $\mathbf{A}, \mathbf{I 3}$, I4 or $\mathbf{3 4}$.

\begin{tabular}{lllll}
\hline Wavelength/wavenumber & $\mathbf{A}^{\mathrm{a}}$ & $\mathbf{I 3}$ & $\mathbf{I 4}$ & $\mathbf{I 3 4}$ \\
\hline $\boldsymbol{\Lambda}$ & & & & \\
ps-TrA $(515 \mathrm{~nm})$ & $410 \pm 40 \mathrm{ps}$ & $650 \pm 80 \mathrm{ps}$ & $820 \pm 100 \mathrm{ps}$ & $820 \pm 190 \mathrm{ps}$ \\
ns-TrA $(515 \mathrm{~nm})$ & $17 \pm 3 \mathrm{~ns}$ & $11 \pm 2 \mathrm{~ns}$ & $28 \pm 3 \mathrm{~ns}$ & $45 \pm 5 \mathrm{~ns}$ \\
ps-TRIR $\left(1680 \mathrm{~cm}^{-1}\right)$ & $460 \pm 70 \mathrm{ps}$ & $790 \pm 120 \mathrm{ps}$ & $780 \pm 120 \mathrm{ps}$ & $\mathrm{nd}^{\mathrm{b}}$ \\
$\boldsymbol{\Delta}$ & & & & \\
ps-TrA $(515 \mathrm{~nm})$ & $730 \pm 70 \mathrm{ps}$ & $520 \pm 50 \mathrm{ps}$ & $790 \pm 80 \mathrm{ps}$ & $590 \pm 60 \mathrm{ps}$ \\
Ns TrA $(515 \mathrm{~nm})$ & $8 \pm 1 \mathrm{~ns}$ & $13 \pm 2 \mathrm{~ns}$ & $11 \pm 2 \mathrm{~ns}$ & $45 \pm 5 \mathrm{~ns}$ \\
ps-TRIR $\left(1680 \mathrm{~cm}^{-1}\right)$ & $860 \pm 130 \mathrm{ps}$ & $740 \pm 110 \mathrm{ps}$ & $1180 \pm 180 \mathrm{ps}$ & $\mathrm{nd}^{\mathrm{b}}$ \\
& & & & \\
\hline
\end{tabular}

${ }^{a}$ data from Keane et al. ${ }^{\text {e }}{ }^{\mathrm{b}}$ nd $=$ not determined due to weak signal. 

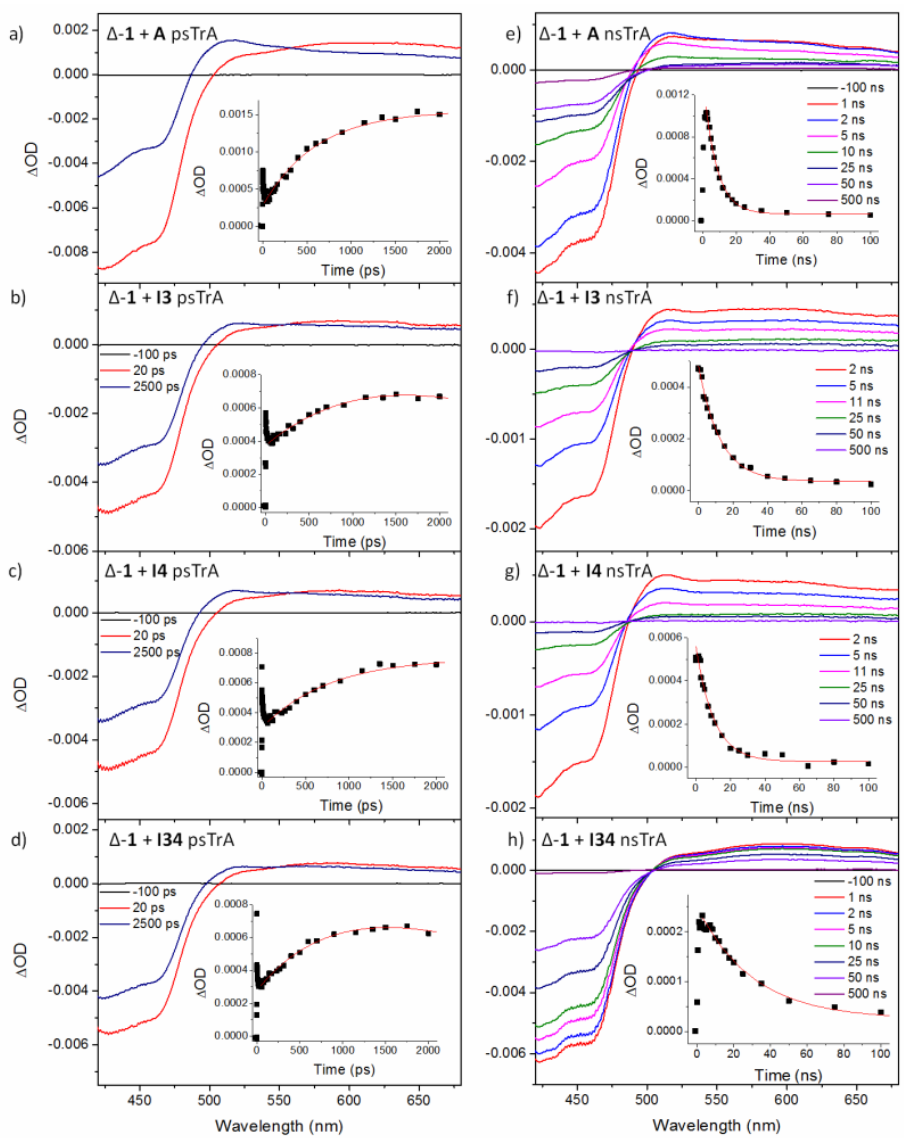

Fig. 4 Comparison of ps/ns-TrA spectra for of $\Delta-\left[\operatorname{Ru}(T A P)_{2}(d p p z)\right]^{2+}$ in the presence of $\mathbf{A}$, $\mathbf{I 3 , I 4 , I 3 4} \lambda_{\text {exc }}=400 \mathrm{~nm}(\mathrm{a}, \mathrm{b}, \mathrm{c}, \mathrm{d}, \mathrm{f}, \mathrm{g}) ; 355 \mathrm{~nm}(\mathrm{e}, \mathrm{h})$ at $1 \mu \mathrm{J}$. Inset: kinetics at $515 \mathrm{~nm}$ (note the differences in strength of signal in the ps data). Data in the presence of $\mathbf{A}^{6 \mathrm{e}}$ shown for comparative 5 purposes. 

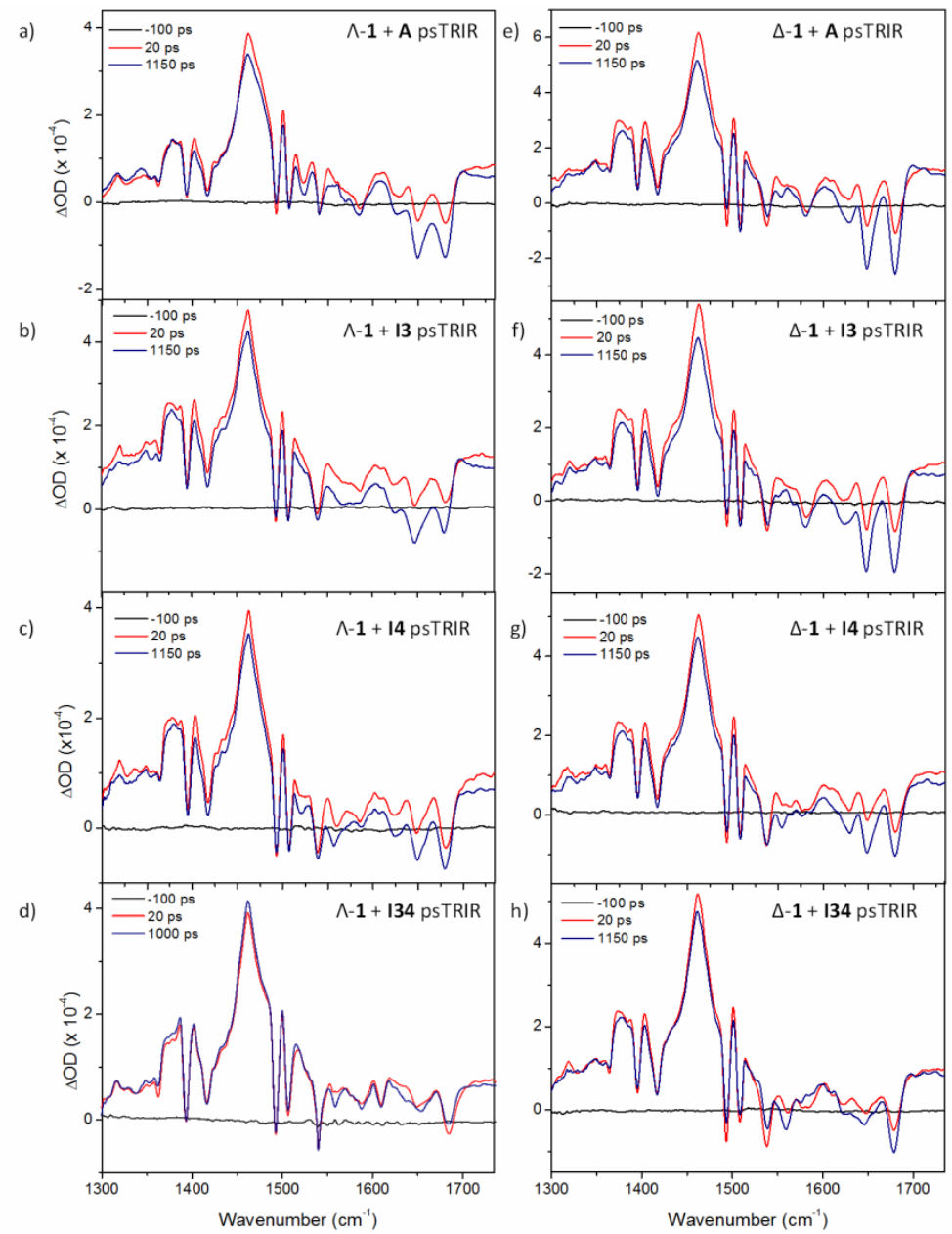

Fig. 5 Comparison of ps-TRIR spectra for of $\Lambda$ and $\Delta$-[Ru(TAP $\left.)_{2}(\mathrm{dppz})\right]^{2+}$ in the presence of $\mathbf{A}, \mathbf{I 3}$, I4 or I34. $\lambda_{\text {exc }}=400 \mathrm{~nm}$. Data in the presence of $\mathbf{A}^{6 \mathrm{e}}$ shown for comparative purposes.

\section{Discussion}

The above experiments show that substituting G3/G4 by inosine in the selfcomplementary duplex sequence $\{\text { TCGGCGCCGA }\}_{2}$ has a major effect on both the yield of electron transfer to photo-excited intercalated $\mathbf{1}$ and on the rates of the subsequent back electron transfer. Given that the oxidation potential for inosine is 10 ca. $200 \mathrm{mV}$ less favourable than guanine ${ }^{9}$ it is unsurprising that the yield of electron transfer (with resultant production of the reduced photosensitiser) is sensitive to this substitution. This effect is expected to be particularly large at G3G4 as GG sites are known to be 'hotspots' for photo-oxidation. ${ }^{8}$ Our data also shows that the oneelectron photo-oxidation depends markedly on the enantiomer employed. This we 15 believe is largely determined by the supramolecular forces controlling the non- 
covalent binding of the metal complex to the DNA. In particular, given that it appears that the electron transfer from guanine to the photoexcited state of $\left[\operatorname{Ru}(\mathrm{TAP})_{2}(\mathrm{dppz})\right]^{2+}$ only occurs when the complex is in contact with a guaninecontaining base-pair, ${ }^{6 f}$ it is likely that any preference for particular base-pair steps 5 will be crucial.

Initially, it is worth considering whether the inosine substitution would have an effect on the secondary structure of the native DNA. Melting studies have shown that G-I substitution causes structural changes extending up to 5 base-pairs away, and which are sequence dependent. ${ }^{17}$ Molecular dynamics simulations ${ }_{10}$ comparing $\{\text { CGCGAATTCGCG }\}_{2}$ and $\{\text { CGCIAATTCGCG }\}_{2}$ reveal an increased intrinsic flexibility of the latter (although no change in curvature relative to the native ODN) possibly due to changes in the hydration of the groove and destacking of the bases. ${ }^{18}$ By contrast, gel mobility experiments suggest that increased curvature may be seen in I subtituted ODNs, ${ }^{11}$ although 15 the X-ray structure of $\{\text { CGCIAATTCGCG }\}_{2}$ shows an isomorphous structure to \{CGCGAATTCGCG $\}_{2}$, with similar structure for both GC and IC sites. ${ }^{10}$ However, it is likely that the presence of the intercalator would provide significant stabilisation to the duplex, and differences in binding preference would be more likely to be caused by removal of $\mathrm{NH}_{2}$ from the intercalation site, than on the 20 secondary structure of the duplex.

In discussing preferences for particular base-steps it is interesting to consider the insights which may be provided by the crystal structures of $\left[\mathrm{Ru}(\mathrm{II}) \mathrm{L}_{2}(\mathrm{dppz})\right]^{2+}$ complexes bound to oligonucleotides. ${ }^{3}$ Such structures have been reported mainly for the $\Lambda$-isomer, so our discussion will focus initially on that enantiomer. It may 25 also be noted that the base-pair steps may be classified as symmetric or asymmetric - the former leading to a perpendicular insertion of the intercalating dppz, while the latter will lead to a canted (or angled) orientation (Figure 6). 


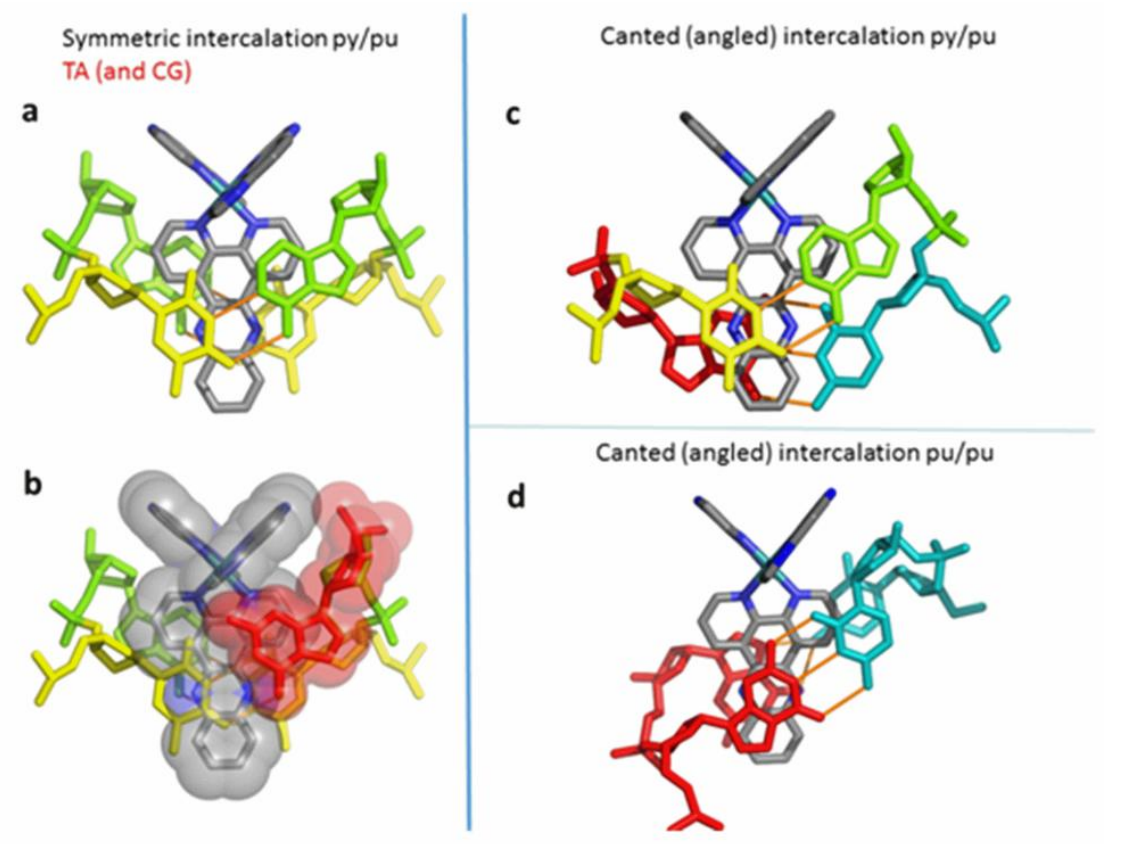

Fig. 6. Binding modes of the $\Lambda$-enantiomer determined by X-ray crystallography for $\{\text { CCGGTACCGG }\}_{2} \cdot{ }^{3 \mathrm{~b}}$ a) Symmetrical intercalation from the minor groove at a TA/TA step $^{3 \mathrm{~b}}$ b) Superimposition of space-filling model of a guanine residue on a) 5 to show the steric clash with the $2-\mathrm{NH}_{2}$ of the guanine base. c) An asymmetric pyrimidine-purine step with asymmetric (angled) intercalation from the minor groove. The CA/TG step. ${ }^{3 \mathrm{e}} \mathrm{d}$ ) fully angled (canted) intercalation at a purine-purine step. The terminal GG/CC step (with Hoogsteen and Watson-Crick basepairs. ${ }^{3 b}$ Colour code for residues : $\mathrm{G}-$ red, $\mathrm{A}-$ green, $\mathrm{C}-$ cyan, $\mathrm{T}-$ yellow. The ruthenium 10 complex is grey, with nitrogen - blue and ruthenium -teal.

In considering the symmetric mode for binding of $\Lambda-\mathbf{1}$ to oligonucleotides it is clear that binding to a TA,TA base step may be preferred. This is apparent from our study on $\{\mathrm{CCGGTACCGG}\}_{2}$ or $\{\mathrm{CCGGATCCGG}\}_{2}$ where it was found that 15 intercalation occurred at the central TA,TA base step, but not at AT,AT. ${ }^{3 \mathrm{~b}}$ This preference is also found with these ODNs in solution and has been shown to have a controlling influence on the yield of electron transfer. ${ }^{6 f}$ Additionally no intercalated complex is found at the central CG,CG step in the crystal structure of $\Lambda-\mathbf{1}$ bound to oligonucleotide $\mathbf{A},{ }^{3 \mathrm{a}}$ which may be taken as an indication that this site is also less 20 favoured than that of TA,TA and which can be correlated with hindrance of binding by the exocyclic amino-group of the guanine (Figure 6). The above results suggest that for these symmetrical sites the order of preference of binding should be in the order TA, TA > CG,CG > AT,AT or GC,GC.

In all the crystal structures we have determined for this family of oligonucleotides, 25 the complex intercalates at the terminal pyr.pyr,pur.pur base step inserting with a canted orientation. ${ }^{3 a, b}$ This suggests that this may also be a favourable binding site in solution, although it should be noted that in the crystal structures, semi-intercalation of a TAP ligand at the G3G4,C7C8 step blocks intercalation at and near this part of 
the duplex and so may give a distorted picture of binding preference. (By contrast, semi-intercalation is expected to be only be a minor component in solution due to a relatively low binding constant. ${ }^{19}$ ) The crystal structure shows that a further important factor in the binding at pur.pur,pyr.pyr base step sites is the overlap of the ${ }_{5} \mathrm{dppz}$ with the purine. We have also found that both enantiomers of $\left[\mathrm{Ru}(\mathrm{phen})_{2}(\mathrm{dppz})\right]^{2+}$ bind at the TG,CA step of d(ATGCAT $)_{2},{ }^{3 \mathrm{c}}$ suggesting that this pyr.pur,pyr.pur base pair step is also a favoured site, as has previously been shown for some classic intercalators. ${ }^{1}$

Turning to consider the inosine-substituted duplexes, it may be noted that the I-C 10 base-pair is electronically and sterically more similar to an AT base-pair than a GC one, when viewed from the minor groove (Fig. 2), the site of intercalation for $\left[\mathrm{Ru}(\mathrm{II}) \mathrm{L}_{2}(\mathrm{dppz})\right]^{2+}$ complexes. It is therefore probable that the distribution of binding sites may be quite different in A, I3, I4 and I34, as it might be expected that a CI,CG base pair step would be a stronger binding site compared to a CG,CG one 15 (see Fig. 2a,b). As noted above, this might have an effect on the yield of ET, as it is normally assumed that binding close to contiguous $\mathrm{G}$ (such as G3G4) gives a high yield. In the case of ODN A, this would mean binding at the C2G3,C8G9 or at the G4C5,G6C7. From the considerations given above the former should be one of the preferred sites for that duplex, while substitution by I of G3 or G4 would generate 20 new base-pair steps C2I3,C8G9 or I4C5,G6C7. The former might be considered a favoured one as it could be considered like a CA,TG site, which would therefore increase the population at that site. On the other hand changing $\mathrm{G} 4 \mathrm{C} 5, \mathrm{G} 6 \mathrm{C} 7$ for I4C5,G6C7 would probably have only a minor effect on the preferred binding site.

Perhaps the most dramatic effect for the $\Lambda$-complex is when both G3 and G4 are ${ }_{25}$ substituted, where the ET appears to be completely eliminated. This might indicate that the complex intercalates at this I3I4,C7C8 site where, of course, it is not in contact with any guanine. As remarked upon earlier, previous studies with $\left[\mathrm{Ru}(\mathrm{TAP})_{2}(\mathrm{dppz})\right]^{2+}$ have suggested that contact of the complex with guanine is necessary for efficient ET. It is also notable that the yield of ET is much more 30 strongly suppressed compared to the unsubstituted A when G4 is replaced with inosine than is the case for I3. This behaviour may be contrasted with that reported by Sistare et al for the oxidation of oligonucleotides by electrochemically-generated $\left[\mathrm{Ru}(\mathrm{bpy})_{3}\right]^{3+} .{ }^{12 \mathrm{c}}$ They reported that the ratio of oxidation rate constants for $5^{\prime}$-GI and $5^{\prime}$-IG steps is $\mathrm{k}_{\mathrm{GI}} / \mathrm{k}_{\mathrm{IG}}=2.8$. Much of the difference between our study and that of ${ }_{35}$ Sistare et al may be attributed to the differing non-covalent binding properties of $\left[\mathrm{Ru}(\mathrm{bpy})_{3}\right]^{2+}$ and $\left[\mathrm{Ru}(\mathrm{TAP})_{2}(\mathrm{dppz})\right]^{2+}$. Thus $\left[\mathrm{Ru}(\mathrm{bpy})_{3}\right]^{2+}$ associates weakly to duplex DNA, probably in the grooves, with relatively little sequence specificity. ${ }^{17}$ By contrast $\left[\mathrm{Ru}(\mathrm{TAP})_{2}(\mathrm{dppz})\right]^{2+}$ (like its structural analog $\left[\mathrm{Ru}(\mathrm{phen})_{2}(\mathrm{dppz})\right]^{2+}$ ) intercalates into the duplex. It is also noteworthy that intercalation into the GG step

40 is likely to perturb the GG stacking that is crucial for lowering the oxidation potential. ${ }^{8}$

Turning to the behaviour of the $\Delta$-enantiomer, it may be noted that in a previous study comparing the $\Lambda-\mathbf{1}$ and $\Delta-\mathbf{1}$ in ODN $\mathbf{A},\left\{(\mathrm{GC})_{5}\right\}_{2}$ and $\left\{\mathrm{G}_{5} \mathrm{C}_{5}\right\}_{2}$, we showed that for $\Delta-\mathbf{1}$ the rates and yield of ET in each sequence varied much less than those for ${ }_{45} \Lambda$-1. Similarly in the current work it is found that the large variations observed for the $\Lambda$-enantiomer are not observed for the $\Delta$-isomer. For example the yield of ET with $\mathbf{I 3 4}$ is about $50 \%$ of that of ODN A, whereas it is tiny for $\Lambda$-1. Additionally it may be noted that the yields of ET with $\Delta-\mathbf{1}$ are similar for I3, I4, or I34, in complete contrast with what is observed for its $\Lambda$ enantiomer. This may imply, as 
was postulated in our previous study, ${ }^{\text {ee }}$ that the GG stack is not as important for $\Delta-\mathbf{1}$ as for $\Lambda-\mathbf{1}$, suggesting that $\Delta-1$ does not bind at this site. Indeed, the removal of both Gs at G3G4 does not reduce the yield to a similar extent compared to $\Lambda \mathbf{- 1}$, which suggests that high yields of ET can be found for $\Delta-\mathbf{1}$ when the sequence contains 5 only single Gs (as previously shown with $\left.\left\{(\mathrm{GC})_{5}\right\}_{2}\right) .{ }^{6 e}$ This is another example of how the enantiomers need to be regarded as distinct species in the context of their DNA-binding behaviour

A notable feature of the TRIR is the presence of DNA bleaches on the ps timescale, before ET occurs. This is most likely due to the association of the 10 excited-state complex with the nucleobases in the intercalation site. Notably, DNA features are also seen when $\Lambda-\mathbf{1}$ is bound to poly $\{\mathrm{dA}-\mathrm{dT}\}_{2},{ }^{6 \mathrm{f}}$ implying that they do not only arise in cases where photo-oxidation is occurring. Such diagnostic features have also been reported in DNA-bound Re complexes, ${ }^{20}$ and may therefore represent a method for assigning the binding site in solution, which can be difficult to achieve

15 using conventional techniques. The TRIR spectra for either $\Lambda \mathbf{- 1}$ or $\Delta \mathbf{- 1}$ bound to I34 both show a larger bleach in the G/I region. It may be noted that, in an I-C base pair, the $\mathrm{C}$ carbonyl does not form a Watson-Crick $\mathrm{H}$ bond, and that the bleach profile shows some resemblance to the IR spectrum of inosine-rich DNAs such as poly\{dI$\mathrm{dC}\}_{2}{ }^{21}$ The physical basis for this interaction is unclear and merits further 20 investigation, although it may be noted that photo-excitation results in a reduced metal centre, which may interact differently in the excited states and ground states.

It is interesting that the rates for the forward ET are quite similar in all cases, while there are larger differences in the decay rate measured in the ns time domain. The forward ET proceeds by transfer of an electron to the $\mathrm{Ru}(\mathrm{III})$ metal centre of the ${ }_{25}$ MLCT excited state. By contrast, the reverse ET involves transfer of an electron from the reduced TAP ligand and as a result, the geometric factors influencing the forward and back ETs in $\left[\operatorname{Ru}(\mathrm{TAP})_{2}(\mathrm{dppz})\right]^{2+}$ are likely to be different. For the forward reaction the distance may be important, but it is also possible that overlap with the dppz ligand may be a significant factor. It has been proposed in 30 computational studies on 1 that a $\pi \pi^{*}$ state on the dppz ligand may have an influence on the ET, ${ }^{22}$ although most experimental evidence, including the TRIR spectra, points to the lowest excited state being of ML(TAP)CT type. The similarity of our TRIR spectra (in the region $1250-1500 \mathrm{~cm}^{-1}$ ) when taken in solution or when the complex is bound to the ODNs strongly suggest that the same state is involved in 35 both media. ${ }^{6 e}$ It is posssible that dppz overlap with the base-pairs contributes to the yield of ET, consistent with earlier reports that stressed the importance of the coupling between stacked units in photo-induced ET with classic intercalators such as thionine. ${ }^{23}$ However it may be noted that the rate of forward ET observed with $\mathbf{1}$ ( $1 / 500 \mathrm{ps}$ ) is slow compared to those photosensitisers. Also it would be misleading 40 to state that the slower rate is purely due to geometric reasons, as the forward ET in the structurally similar $\left[\mathrm{Cr}(\mathrm{phen})_{2}(\mathrm{dppz})\right]^{3+}$, which would be expected to bind similarly to DNA, occurs in less than 10 ps. ${ }^{24}$ Whether the difference between the $\mathrm{Cr}(\mathrm{III})$ and the $\mathrm{Ru}(\mathrm{II})$ complexes is a consequence of energetics (the redox potential of the excited state of the $\mathrm{Cr}(\mathrm{III})$ is approximately $0.1 \mathrm{eV}$ higher) or to a change in 45 mechanism (from direct ET to proton-coupled) will require further investigation.

\section{Concluding Remarks}

In conclusion this study shows that while replacing the guanosine nucleoside by 
inosine is not expected to affect the overall structure of the DNA duplex it can affect the nature of the binding sites, resulting in unexpected changes in the yield of electron transfer in certain cases. This is a further example of the sensitivity of small changes in DNA sequence, in this case the removal of a single $\mathrm{NH}_{2}$ group in a 5 decamer strand, on the binding mode of $\mathrm{Ru}(\mathrm{II}) \mathrm{dppz}$ complexes. Furthermore this highlights that the use of inosine substitution as a control experiment for guanine photo-oxidation should be performed with care, especially where the photosensitiser of interest binds from the minor groove. We are currently investigating the photophysics and crystal structures of $\left.[\operatorname{RuTAP})_{2}(\mathrm{dppz})\right]^{2+}$ enantiomers bound to

10 other ODNs, and it is anticipated that this will allow further insight into the relationship between DNA binding site and electron transfer dynamics for these complexes, and also on the binding modes and preferences that are common to both the crystal state and solution.

\section{${ }_{15}$ Acknowledgements}

This work was supported by BBSRC grant BB/K019279/1 Royal Irish Academy/ Royal Society exchange programme, STFC for programmed access to the CLF (App 13230047), the School of Chemistry and Chemical Biology, UCD (SJQ), Science Foundation Ireland (TG) and the Irish Research Council (FEP).

\section{${ }_{20}$ Notes and References}

${ }^{a}$ School of Chemistry, Trinity College, Dublin 2, Ireland; keanepa@tcd.ie; jmkelly@tcd.ie

${ }^{b}$ Dept. of Chemistry, University of Reading, Whiteknights, Reading, RG6 6AD, UK; c.j.cardin@rdg.ac.uk

${ }^{c}$ Trinity Biomedical Science Institute, Pearse St., Dublin 2, Ireland

${ }_{25}^{d}$ Diamond Light Source, Harwell Science and Innovation Campus, Oxfordshire, OX11 0QX, $U K$

e Central Laser Facility, Research Complex at Harwell, STFC Rutherford Appleton Laboratory, Harwell Science and Innovation Campus, Oxfordshire, OX11 OQX, UK

${ }^{f}$ School of Chemistry, University College Dublin, Dublin 4, Ireland

30

${ }^{\dagger}$ If it is assumed that at 20 ps after the laser pulse the only transient species present is the excited state having an absorption coefficient $\varepsilon_{\mathrm{es}}$, then the change in absorbance $\left(\Delta \mathrm{OD}_{20 \mathrm{ps}}\right)$ will be proportional to $\left(\varepsilon_{\mathrm{es}}-\varepsilon_{\mathrm{gs}}\right)$, where $\varepsilon_{\mathrm{gs}}$ is the absorption coefficient of the ground state at the same wavelength. If the excited state were to be converted $100 \%$ to the reduced complex, then $\Delta \mathrm{OD}$ after

35 reaction will be proportional to $\left(\varepsilon_{\mathrm{red}}-\varepsilon_{\mathrm{gs}}\right)$, where $\varepsilon_{\mathrm{red}}$ is the absorption coefficient of

$\left[\operatorname{Ru}(\mathrm{TAP})_{2}(\mathrm{dppz})\right]^{+}$. If only a fraction $(\mathrm{x})$ of the excited states is so converted, then $\Delta \mathrm{OD}$ is proportional to $\mathrm{x}\left(\varepsilon_{\mathrm{red}}-\varepsilon_{\mathrm{gs}}\right)+(1-\mathrm{x})\left(\varepsilon_{\mathrm{es}}-\varepsilon_{\mathrm{gs}}\right)$. If we assume that at $2500 \mathrm{ps}$ any reaction of the excited state on the picosecond timescale is complete and that the only process excited states have undergone is reduction giving $\left[\mathrm{Ru}(\mathrm{TAP})_{2}(\mathrm{dppz})\right]^{+}$, then $\left(\Delta \mathrm{OD}_{2500 \mathrm{ps}}-\Delta \mathrm{OD}_{20 \mathrm{ps}}\right) / \Delta \mathrm{OD}_{20 \mathrm{ps}}=\mathrm{x}\left(\varepsilon_{\mathrm{red}}-\right.$

$\left.40 \varepsilon_{\mathrm{es}}\right) /\left(\varepsilon_{\mathrm{es}}-\varepsilon_{\mathrm{gs}}\right)$, so that comparing this parameter with various ODNs gives a measure of the relative yield of electron transfer.

1 S. Neidle, Nucleic Acid Structure and Recognition, 2002, Oxford University Press.

2 (a) J. K. Barton, Science, 1986, 233, 727-734; (b) C. Hiort, P. Lincoln and B. Norden, J. Am. Chem. Soc., 1993, 115, 3448-3454.

3 (a) J. P. Hall, K. O'Sullivan, A. Naseer, J. A. Smith, J. M. Kelly and C. J. Cardin, Proc. Natl. Acad. Sci. (USA), 2011, 108, 17610-17614; (b) H. Niyazi, J. P. Hall, K. O’Sullivan, G. Winter, T. Sorensen, J. M. Kelly and C. J. Cardin, Nat. Chem., 2012, 4, 621-628; (c) J. P. Hall, H. Beer, K. Buchner, D. J. Cardin and C. J. Cardin, Phil. Trans. R. Soc. A, 2013, 371, 20120525-20120532; (d) H. Song, J. T. Kaiser and J. K. Barton, Nat. Chem., 2012, 4, 615-620; (e) J. P. Hall, D. Cook, S. R. Morte, P. McIntyre, K. Buchner, H. Beer, D. J. 
Cardin, J. A. Brazier, G. Winter, J. M. Kelly and C. J. Cardin, J. Am. Chem. Soc., 2013, 135, 12652-12659. (f) J. P. Hall, H. Beer, K. Buchner, D. J. Cardin and C. J. Cardin, Organometallics, 2015, 34, 2481-2486

4 (a) N. A. Smith and P. J. Sadler, Phil. Trans. R. Soc. A, 2013, 371, 20120519- 20120532;

(b) E. Wachter, D. K. Heidary, B. S. Howerton, S. Parkin and E. C. Glazer, Chem. Commun., 2012, 48, 9649-9651; (c) M. R. Gill and J. A. Thomas, Chem. Soc. Rev., 2012, 41, 3179-3192; (c) C. A. Puckett and J. K. Barton, J. Am. Chem. Soc., 2007, 129, 46-47; (d) R. B. P. Elmes, K. N. Orange, S. M. Cloonan, D. C. Williams and T. Gunnlaugsson, J. Am. Chem. Soc., 2011, 133, 15862-15865; (e) A. M. Palmer, S. J. Burya, J. C. Gallucci and C. Turro, ChemMedChem, 2014, 9, 1260-1265; (f) L. Marcélis, C. Moucheron and A. Kirsch - De Mesmaeker, Phil. Trans. R. Soc. A, 2013, 20120131; (g) S. M. Cloonan, R. B. P. Elmes, M.L. Erby, S. A. Bright, F.E. Poynton, D. E. Nolan, S. J. Quinn, T. Gunnlaugsson, and D. C. Williams, J. Med. Chem., 2015, 58, 4494-4505

5 (a) A. E. Friedman, J-C. Chambron, J-P. Sauvage, N. J. Turro and J. K. Barton, J. Am. Chem. Soc., 1990, 112, 4960-4962; (b) A. W. McKinley, P. Lincoln and E. M. Tuite, Coord. Chem. Rev., 2011, 255, 2676-2692; (c) A. Greguric, I. D. Greguric, T. W. Hambley, J. R. Aldrich-Wright and J. G. Collins, J. Chem. Soc., Dalton Trans., 2002, 849-855.

6 (a) C. G. Coates, P. Callaghan, J. J. McGarvey, J. M. Kelly, L. Jacquet and A. Kirsch-De Mesmaeker, J. Mol. Struc., 2001, 598, 15-25; (b) I. Ortmans, B. Elias, J. M. Kelly, C. Moucheron and A. Kirsch DeMesmaeker, Dalton Trans. 2004, 668-676; (c) B. Elias, C. Creely, G. W. Doorley, M. M. Feeney, C. Moucheron, A. Kirsch - DeMesmaeker, J. Dyer, D. C. Grills, M. W. George, P. Matousek, A. W. Parker, M. Towrie and J. M. Kelly, Chemistry - Eur. J., 2008, 14, 369-375; (d) J.A. Smith, M. W. George and J.M. Kelly, Coord. Chem. Rev., 2011, 255, 2666- 2675; (e) P. M. Keane, F. E. Poynton, J. P. Hall, I. P. Clark, I. V. Sazanovich, M. Towrie, T. Gunnlaugsson, S. J. Quinn, C. J. Cardin and J. M. Kelly, J. Phys. Chem. Lett., 2015, 6, 734-738; (f) P. M. Keane, F. E. Poynton, J. P. Hall, I. V. Sazanovich, M. Towrie, T. Gunnlaugsson, S. J. Quinn, C. J. Cardin and J. M. Kelly, Angew. Chem., in press. DOI: 10.1002/anie.201502608R1 and 10.1002/ange.201502608R1.

7 a) J.-P. Lecomte, A. Kirsch-De Mesmaeker, M. M. Feeney and J. M. Kelly, Inorg. Chem. 1995, 34, 6481; (b) L. Jacquet, R. J. H. Davies, A. Kirsch-De Mesmaeker and J. M. Kelly, J. Am. Chem. Soc. 1997, 119, 11763-11768.

8 I. Saito, T. Nakamura, K. Nakatani, Y. Yoshioka, K. Yamaguchi and H. Sugiyama, J. Am. Chem. Soc., 1998, 120, 12686-12687.

9 J. K. Barton, E. D. Olmon and P. A. Sontz, Coord. Chem. Rev., 2011, 255, 619-634.

10 J.-C. Xuan and I. T. Weber, Nucleic Acids Res., 1992, 20, 5457-5464.

11 C. Bailly, D. Suh, M. J. Waring and J. B. Chaires, Biochemistry, 1998, 37, 1033-1045.

12 (a) S. O. Kelley and J. K. Barton, Science, 1999, 238, 375-381 (b) C. Wan, T. Fiebig, O. Schiemann, J. K. Barton and A. H. Zewail, Proc. Natl. Acad. Sci. U. S. A., 2000, 97, 14052-14057; (c) M. F. Sistare, S. J. Codden, G. Heimlich and H. H. Thorp, J. Am. Chem. Soc., 2000, 122, 4742-4749; (d) F. Shao, M. A. O’Neill and J. K. Barton, Proc. Natl. Acad. Sci. U. S. A., 2004, 101, 17914-17919.

13 A. W. McKinley, J. Andersson, P. Lincoln and E. Tuite, Chem. Eur. J., 2012, 18, $15142-$ 15150.

14 M. Towrie, G. W. Doorley, M. W. George, A. W. Parker, S. J. Quinn and J. M. Kelly, Analyst, 2009, 134, 1265-1273

15 (a) G. M. Greetham, P. Burgos, Q. Cao, I. P. Clark, P. S. Codd, R. C. Farrow, M. W. George, M. Kogimtzis, P. Matousek, A. W. Parker, M. R. Pollard, D. A. Robinson, Z. J. Xin and M. Towrie, Appl. Spectrosc., 2010, 64, 1311-1319; (b) G. M. Greetham, D. Sole, I. P. Clark, A. W. Parker, M. R. Pollard, M. Towrie, Rev. Sci. Instrum. 2012, 83, 103107.

16 A. W. Parker, C. Y. Lin, M. W. George, M. Towrie and M. K. Kuimova, J. Phys. Chem. $B, 2010,114,3660-3667$.

17 N. O. Reich and K. R. Sweetman, Nucleic Acids Res. 1994, 22, 2089-2093

18 B. Wellenzohn, W. Flader, R. H. Winger, A. Hallbrucker, E. Mayerm and K. R. Liedl, Nucleic Acids Res. 2001, 29, 5063-5043

19 P. Lincoln and B. Norden, J. Phys. Chem. B, 1998, 102, 9583-9594. 
20 Q. Cao, C. M. Creely, J. Dyer, T. L. Easun, D. C. Grills, D. A. McGovern, J. McMaster, J. Pitchford, J. A. Smith, X.-Z. Sun, J. M. Kelly and M. W. George, Photochem. Photobiol. Sci. 2011, 10, 1355-1364.

21 L. Wang and T. A.Keiderling, Nucleic Acids Res., 1993, 21, 4127-4132.

22 (a) T. Very, D. Ambrosek, M. Otsuka, C. Gourlaouen, X. Assfeld, A. Monari, C. Daniel, Chem. Eur. J. 2014, 20, 12901-12909; (b) C. Daniel, Coord. Chem. Rev. 2015, 282, 1932.

23 G. D. Reid, D. J. Whittaker, M. A. Day, D. A. Turton, V. Kayser, J. M. Kelly and G. S. Beddard, J. Am. Chem. Soc., 2002, 124, 5518-5527.

24 S. J Devereux, P. M. Keane, S. Vasudevan, I. V. Sazanovich, M. Towrie, Q. Cao, X.-Z. Sun, M. W. George, C. J. Cardin, N. A. P. Kane-Maguire, J. M. Kelly, S. J. Quinn, Dalton Trans. 2014, 43, 17606-17609. 